\title{
New sources for a new history.
}

\author{
Camille Akmut
}

\begin{abstract}
Historians will need to abandon their ideals of only working with books and traditional sources, if they wish to do anything original in this century. More references for the history and sociology of computer science and technology; in the hopes, still, of creating many others.
\end{abstract}

28 October 2018

05:31 alyssa changed the topic of \#panfrost to: Panfrost - FLOSS Mali Midgard \& Bifrost $(\ldots)$

$22: 16<$ HdkR> Spooky blob writers

22:16 <alyssa> HdkR: Hey, I know what I'm going as for Halloween!

$(\ldots)$

22:23 <ente> given that a blob writer looks just like a normal programmer with some standard

$22: 23<a l y s s a>: v$

$22: 23$ <ente> maybe that's the creepy part, we could all be blob writers. (...)

$22: 24$ <alyssa> I wouldn't write blobs

$22: 24$ <ente> you say that now.

$22: 24$ <ente> *thunder*

$22: 24$ <alyssa> ...I mean I guess if money got really tight T_T

22:25 <ente> I'd like to see more FOSS funding in the EU

$22: 27<$ HdkR> ente: I'm supposed to have standards?!

$22: 27 *$ HdkR has been doing it wrong 


\section{Introduction : "real" archives}

In one discussion amongst colleagues, the topic of archives had come up : I had been skipped. For, what archives - "real" archives it is understood, of course - could a historian of computer science and technology know?

I had been an archivist for 2 years at the Canguilhem Center for the history and philosophy of sciences, and had gone through a thousand and a thousand more documents (letters, pre-prints, tax filings, invitations, ...) culminating in a hundred-page inventory : and, during that time, had known more archives than many historians will ever know, "even in their wildest dreams". Add the National Archives and College de France.

It is, from these experiences, that we would like to think that we know better when it comes to "real" archives. But, so-called "real archives" are only promoted by "unreal" historians - the laughing subject and laughingstock of all others.

They fled persecution from people being persecuted.

A reference our unreal historians will never get, and thus it will be of no surprise to anyone, that, not only will they never do, or accomplish anything original in their works, to say nothing of their lives, of which there is nothing to say otherwise, but will never be able to write a good cultural or social history of computer science, or technology, or anything of the 21st century.

They do not understand themselves, but how do they expect to understand their subjects? We cannot help them : they must help themselves.

Among historians, Michel Foucault occupies a special place, and certainly a very special one in our hearts : he who turned out to practice history better than all of them, who had rejected him for so long :

His fate reminds us of the judgments of Lenin on those we will call with no qualms "giggolo intellectuals", and who were the scholar weathercocks of his days, and those of Marx :

German bourgeois scholars, only yesterday specialists in the annihilation of Marxism, are speaking [now] of the 'nationalGerman' Marx ${ }^{1}$

We could go on and on about these third-rate intellectuals, but it gives us no pleasure.

In one of our last publications in our series "What is computer science? On two crises", we draw lessons from a recently published report.

Our work has taken on, strangely, the same patterns and methods as those of our objects.

But, we retain our own vision, and see science, still, through own glasses : when previously fervent defenders of free software now use the language of "open source", we cannot help but take note. This, however, is not a history, or sociology, that we will, or are willing to write.

${ }^{1}$ The State and Revolution, Chapter 1 . (If only one must or can be read, this one.) 
They have perhaps drawn the lessons from life that, some of us very early on, and some of us try to push back as long as we can, we are taught : that it is better to bend to life, than being bent by it. These non-tenacious realists do many things, except make us dream.

But, if we let them rob us of our dreams, we let them rob us of lives, and if we give up on them, we give up on ourselves - so, thought at least two queer writers. 


\section{Sources}

○ - 2019. "Freedom in computing : Libreboot, Panfrost report."

Description : I should have insisted more on the role of Lyude Paul, the other creator of Panfrost; I did not name Connor Abbott, another main contributor to this project; And, also failed to mention Qiang Yu's work; For lack of knowledge.

$\checkmark$ Rosenzweig, Alyssa. 2018. "Midgard Shaders with the Free NIR Compiler". 18/03. https://rosenzweig.io/blog/midgard-shaders-with-the-freenir-compiler.html

Description : History and historians who write it tend to remember those who in addition to doing also document their doings. Leading to a biased version of events, and the respective role and importance of those involved in them. In previous eras, birth, gender and color of skin played also a disproportionate role in highlighting the makers of not only science.

"On a note of administrivia, the project name has been properly changed to Panfrost. For some history, over the summer two driver projects were formed: chai, by me, for Midgard; and BiOpenly, by Lyude et al, for Bifrost. Thanks to Rob Clark's matchmaking, we found each other and quickly realised that the two GPU architectures had identical command streams; it was only the shader cores that were totally redesigned and led to the rename. Thus, we merged to join efforts (...)"

$\odot$ https://freenode.irclog.whitequark.org/panfrost/

Description : Panfrost \#panfrost IRC channel logs (archives going back to October 27th 2018).

$\odot$ https://gitlab.freedesktop.org/lima

Description : "Open-source reverse-engineered driver for Mali-4xx GPUs". Continuation of the Lima driver by Qiang Yu.

$\odot$ https://lists.freedesktop.org/archives/lima/

Description : (new) Lima discussion list (archives going back to June 2018). 